\section{Flights of fancy}

The 980 species of bat have many remarkable features and show huge diversity. It is well known that they use echolocation to navigate and detect prey - hence the large ears of the long-eared bat, Plecotus sp., shown here. But the role of bats in seed dispersal and controlling insect populations is often overlooked, and without pollination by bats there would be no tequila. Now they are under threat, from habitat destruction and the use of pesticides, a recurring theme in Bats (The Natural History Museum, £9.95) by Phil Richardson,
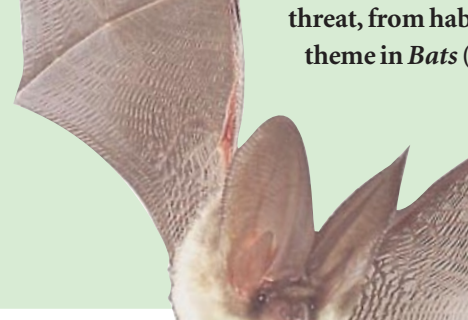

is to be defended, this has to be on metaphysi-

cal grounds that go beyond the simply scientific. Although the judgement may seem odious, to imply otherwise is indeed an act of physics imperialism.

Another significant metaphysical issue is the status of values, such as ethical insights. Weinberg frequently affirms the importance of values, and he does not claim that they are something for which science itself can establish a basis. He sees them as human creations, by which we make for ourselves a little island of meaning in the hostile and meaningless Universe that surrounds us. There is a certain nobility in this bleak view, but I believe it to be mistaken. Our ethical intuition that abusing children is wrong is not simply something we have decided to assert. It is an actual fact about the complex reality within which we live, a form of knowledge whose origin is a question that requires very careful consideration. A true rationality has to take the reality of this kind of personal experience as seriously as it does science's impersonal encounter with the world.

This latter kind of reasoning is part of my motivation for being a religious believer. Weinberg is well known as an implacable opponent of religion. One of the essays in this volume arose from a conference to which we both contributed, which was convened to discuss whether there are any signs of inbuilt design in the Universe. Much of the argument related to the 'Anthropic Principle', the surprising recognition that a universe capable of generating carbon-based life has to satisfy very tight conditions on the strengths of the forces of nature operating within it. Weinberg refers to these matters from time to time, particularly noting the astonishingly tiny value $\left(10^{-120}\right.$ of its naturally expected strength) that the cosmological constant has to take in an anthropic world. He takes the multiverse way out, avoiding any whiff of theism by appealing to the highly speculative and metaphysically prodigal notion that our world is just, by chance, the anthropically who was recently appointed by Britain's National Trust as their first bat conservation officer. fruitful member of a vast portfolio of diverse universes.

When Weinberg comments more generally on religion, the tone is highly polemical. He is right to draw attention to the horrors of religious wars and persecutions, for which a believer must feel shame and penitence, even if such terrible happenings are by no means the monopoly of religions. Yet that dark side is far from being the whole story, for much good and achievement (including initially modern science, some would claim) have also come out of religious belief. Weinberg rightly raises the issue of suffering, asking "how does free will account for cancer?" It does not, but an evolving world (theologically, a creation allowed to 'make itself') is one in which cellular mutations necessarily bring about not only new forms of life, but also malignancy.

This is an interesting book, with a lot to question and (I believe) disagree with, but is well worth reading.

John Polkinghorne is the retired president of Queens' College, Cambridge, CB3 9ET, UK. His latest book, published this month, is

The God of Hope and the End of the World (Yale University Press, 2002). He was awarded the Templeton Prize for Progress in Religion on 14 March 2002.

\section{It's not all in the}

\section{genes}

\section{Phenotypic Plasticity: Beyond \\ Nature and Nurture}

by Massimo Pigliucci

Johns Hopkins University Press: 2001. 384 pp. $\mathfrak{£} 25, \$ 75$

\section{Ralph Tollrian}

Phenotypic plasticity describes the ability of a genotype to form different phenotypes in distinct environmental conditions. Although originating in the field of evolutionary biology, phenotypic plasticity is a truly interdisciplinary topic, lying at the intersection between most of today's important biological disciplines, from evolution to molecular biology and, of course, ecology. Phenotypic plasticity occurs in many traits ranging from morphology through developmental biology to physiology and behaviour, and can be found in all classes of organism. Nearly every biological discipline deals with some aspects of phenotypic plasticity.

Massimo Pigliucci's Phenotypic Plasticity: Beyond Nature and Nurture is the first volume in a new series entitled "Syntheses in Ecology and Evolution" edited by Sam Scheiner. Both scientists are leading experts in the field of phenotypic plasticity, and their names are a guarantee of a high standard.

It is a good time for a book on this topic. Following the renaissance of the 'reaction norm' (a term coined by Woltereck in 1909, referring to a set of phenotypes expressed by an individual genotype in response to an environmental gradient), a wealth of papers in the past two decades has described phenotypic plasticity and genotype-environment interactions. Whether phenotypic plasticity is a target or a by-product of selection has been hotly debated, which has led to the realization that it can be both. Now, thanks to the rapid development of molecular techniques, the field is at a stage where new questions can be asked. What are the developmental mechanisms? What are the pathways? How does a genotype map into a phenotype? When does selection lead to the evolution of distinct morphs or even species, and when to phenotypic plasticity? Pigliucci pinpoints these key questions with a focus on mechanisms and processes.

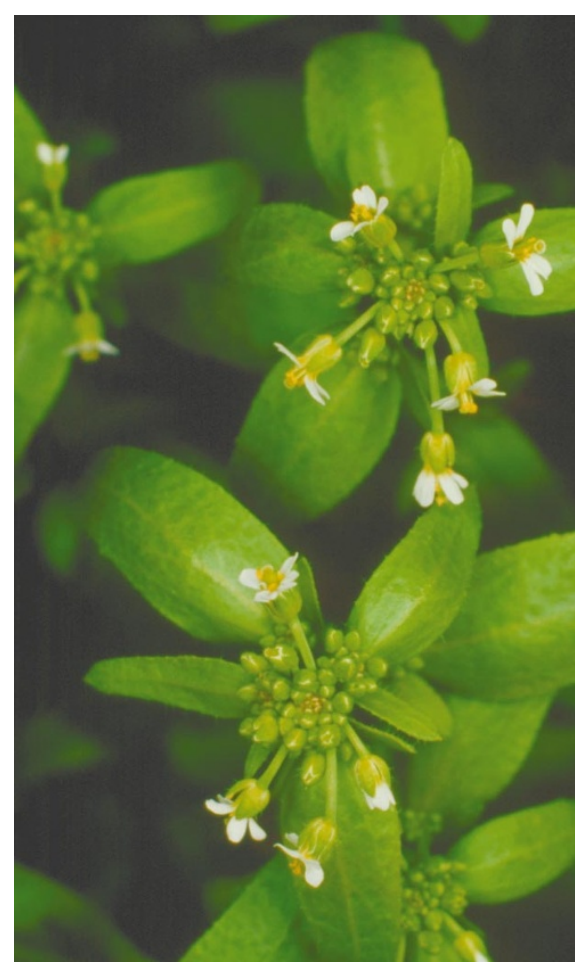

Working model: thale cress (Arabidopsis thaliana) is often used in studies of phenotypic plasticity. 
A strength of the book is Pigliucci's attempt to outline avenues for future research. Following a general introduction to phenotypic plasticity, he gives a broad overview of the recent contributions of genetics, molecular biology, developmental biology, ecology, behavioural biology, evolutionary biology and theory to a modern synthesis of phenotypic plasticity. He then emphasizes, using Arabidopsis thaliana as an example, how research on phenotypic plasticity can lead to insights into other fields of evolutionary biology. In the final chapter, he extends the scope of the book beyond 'nature and nurture' to socio-political aspects of the question of how genes and environment influence human intelligence.

Phenotypic plasticity has been a battlefield for many, sometimes semantic, controversies. Pigliucci gives a balanced presentation, separating his own from alternative opinions. Nevertheless, there remain many anchor points for stimulating discussions. For example, he emphasizes that plasticity in morphology, physiology and behaviour share a general framework, but suggests that one should distinguish between these fields, because timing and mechanisms differ. An alternative view would be that it is exactly the interplay between these differences that creates a promising area of research.

The book demonstrates Pigliucci's unusually broad knowledge of the topic. However, it is impossible to cover all aspects of phenotypic plasticity within the publisher's page limits for a single book. Consequently, he deals with some topics only briefly. For example, the factors that favour the evolution of phenotypic plasticity (R. Tollrian and C. D. Harvell, The Ecology and Evolution of Inducible Defenses, Princeton University Press, 1999) would, in my opinion, have benefited from more space.

Although there is some overlap with an earlier book on phenotypes by C. D. Schlichting and Pigliucci (Phenotypic Evolution: A Reaction Norm Perspective, Sinauer, 1998), Phenotypic Plasticity is the most comprehensive book on this topic. It provides both a solid basis for understanding the subject and an inspiring synthesis of the current state of the discipline, and so can be equally recommended for students starting their research, for experts in the field and for all scientists generally interested in phenotypic plasticity. Hardly anyone will read this book without gaining new insights or new inspirations. The book is a 'must read' in the fields of evolution and ecology, and as such is an ideal topic for seminars. I highly recommend it and look forward to the next volumes in Scheiner's series.

Ralph Tollrian is in the Department of Evolutionary Ecology, Ludwig-MaximiliansUniversität München, Karlstrasse 23-25,

München D-80333, Germany.

\section{Science in culture}

\section{Infinite ideas}

A theatrical contemplation of infinity makes full use of industrial space.

Roald Hoffmann and Sylvie Coyaud

There's science in the theatre - Michael Frayn's Copenhagen, Peter Parnell's Q.E.D., and Oxygen by Carl Djerassi and one of us. And now there is Luca Ronconi and John Barrow's Infinities. Italy's most innovative director has staged in Milan a remarkable theatro-architectonic meditation on, indeed, infinity.

Five pieces of text were written for the play by John Barrow, quoting Jorge Luis Borges, the physicist-novelist Alan Lightman and the mathematician Georg Cantor, among others. The texts are integrated by Ronconi's vision into a journey of engrossing variety. In Milan's industrial section, Bovisa, La Scala Opera company had refurbished some old buildings for its workshops. This is Ronconi's setting. Or better said, settings, for the audience moves from one space in the vast complex to another.

One begins in a bar atrium, rising eight floors: L'Albergo Infinito, or the Hilbert Hotel as mathematicians may know it, whose manager must accommodate an infinite number of guests. He rehearses different solutions and proves some theorems along the way. Next, in a windowless room, women young and old alternate between desire and dread of living forever. Elsewhere, the paradoxes of time travel are paraded around a large hangar, that has a train carriage suspended in mid-air at one end and crates of books at the other.

The actors pass through the audience, and in one effective scene, where Cantor's work and life is told, we sit at tables with students/actors from Milan Polytechnic University. Other actors walk on the tables, climb ladders, or speak

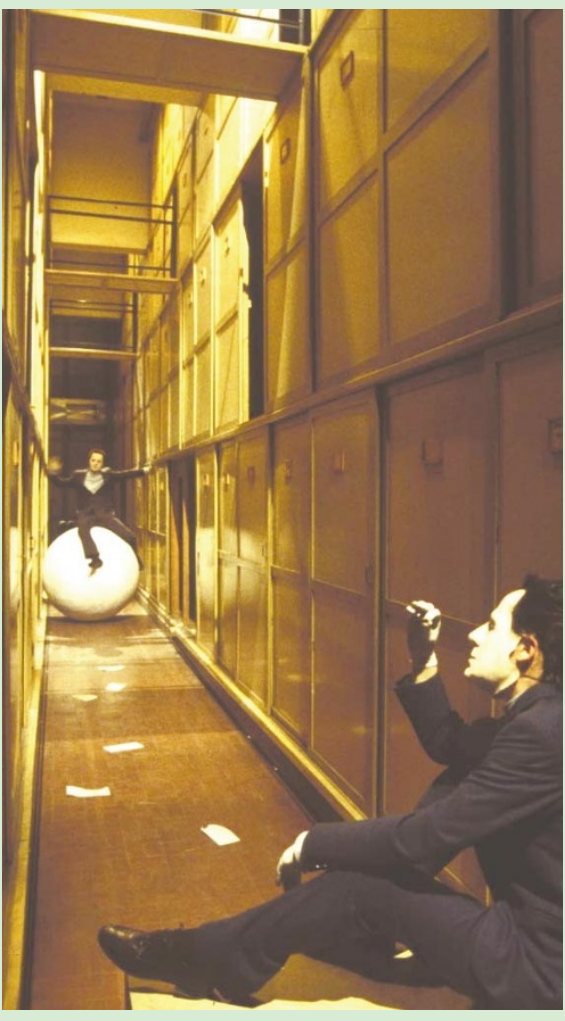

suspended upside-down from a conveyor belt. Their tight face masks, black and white costumes and moving platforms are all Ronconi's hallmark.

The most successful, indeed unforgettable, of the scenes accomplishes what we thought could not be done - it recreates on stage Borges' Library of Babel. A cavernous space, several stories high, is filled with cubicles and empty bookcases, two slanted mirrors stretching them effectively to infinity. Narrators appear on passages and bridges, making a connection not only to Borges' dismal library, but also to Andrea Palladio's theatre at Vicenza.

The audience is admitted in groups of 60 to 80 every 15 minutes, and moves through the five sets in roughly two hours. Meanwhile the actors, a large cast, also rotate, adding to the sense of endless motion.

Do we learn any mathematics? Yes. Does it matter? Not at all. This is a theatre of space and time, and of ideas. It is abstract, for the dramatic moments come not in confrontation of human beings, in that silence between words and action where a gesture stretches time; rather, they come from the tug-of-war between hope and despair, or comic failure. To the mind bold enough to pursue it, we are shown, infinity promises unlimited freedom — and delivers madness.

The Piccolo Teatro production, sponsored by Fondazione Sigma Tau, ran for just three weeks in Milan, ending on 28 March. On 19 April it will inaugurate the "Ciutat de les Arts Escéniques”, created by Spain's leading architect, Santiago Calatrava, in another former factory, the Nave de Sagunto in Valencia. Given the integration of theatre with setting, the play cannot be the same. One is curious to see how the Spanish director Vincente Genovès will translate Ronconi's vision into the soaring Nave, and whether the cast, coached by the Greek actress Irene Papas, will match the bravura of the Piccolo's performance.

Roald Hoffmann is professor of chemistry at Cornell University, Ithaca, New York. Sylvie Coyaud is a science journalist based in Milan.

For details on the production, in Italian, see http://www.piccoloteatro.org/infinities 